\title{
The effect of dissolved oxygen on microgreen productivity
}

\author{
Alexander Grishin*, Andrey Grishin, Natalia Semenova, Vladimir Grishin, Inna Knyazeva, and Alexey Dorochov
}

Federal State Budgetary Scientific Institution «Federal Scientific Agroengineering Center VIM», Moscow, Russia

\begin{abstract}
The effect of oxygen dissolved in water was researched $(1.3 \mathrm{mg} / \mathrm{l}$ - without saturation, $6.1 \mathrm{mg} / \mathrm{l}$ - air saturation, $14.7 \mathrm{mg} / \mathrm{l}$ - oxygen saturation) on the microgreen productivity of "Ivolga" variety wheat of and 'Aida' variety lentils. It was found that the enrichment of water for seed germination with oxygen stimulates the speedy germination and receipt of wheat and lentils sprouts 1 day faster than in the variant without saturation. An increase in oxygen concentration contributes to the rapid root system growth of the researched cultures, stimulates the formation of 2 order roots, accelerates the development of the overhead plant parts without dry weight loss. On the 7th day of cultivation, the wet weight of wheat increased by 21 $\%$ in the variant with air saturation and 56\% with oxygen saturation, wet weight of lentils - by $57 \%$ and 77 $\%$, respectively. Both a deficiency and an excess of oxygen in water can adversely affect the content of basic pigments. Therefore, it is necessary to select the species composition of cultures for composing multicomponent mixtures, to obtain higher microgreen quality when grown on oxygen-rich solutions.
\end{abstract}

\section{Introduction}

The world's population is increasing every year, and the urban population is also growing rapidly. Among urban residents, natural and environmentally friendly products, including food, are gaining popularity, while confidence in large manufacturers is declining. Against this background, city farming has developed.

According to "Research and Markets", the global vertical farming market in 2017 amounted to about $\$ 2.3$ billion, and by 2023 it will grow to almost $\$ 7.5$ billion, adding more than $20 \%$ annually. City farmers are able to solve the main problem of traditional agriculture complex logistics [1].

In recent years, a new trend in nutrition has emerged - eating sprouts or "Baby Leaf" and microgreens (young green shoots up to $15 \mathrm{~cm}$ long, depending on the crop) to enrich the diet with minerals and vitamins $[2,3]$. The nutrient content in microgreens is several times greater than in an adult plant [4-6].

Microgreens are characterized by an increased concentration of vitamin C [7], which is lost during heat treatment, in addition, after collection, it quickly loses moisture and nutritional value, so it is so important to use it fresh [8].

The microgreen is rich in chlorophyll, which strengthens the immune system, promotes the healing of wounds and ulcers, and is a natural cancer protector [9]. The chemical structure of chlorophyll is similar to human hemoglobin, therefore, the consumption of microgreens contributes to the process of hematopoiesis, improves oxygen supply to the lungs, optimizes the function of internal organs, and also prevents hypercholesterolemia [10].

There are various methods of microgreens growing. The traditional method is cultivation in soil or peat, where the seed germination occurs in containers filled with soil substrate. Sometimes, special paper towels, perlite, coconut fiber substrates, linen rugs, jute-kenaffiber and biodegradable polylactic acid materials are used as a substrate. In industrial cultivation, a nonsubstrate technology is used - aeroponics or hydroponics [11].

Hydroponics ensures that the root area is saturated with all the necessary building elements and more intensive growth, in comparison with the soil method, but the solution is practically not enriched with natural oxygen, which often leads to the development of pathogenic microflora [12]. By forming the first pair of leaves, the microgreen seedling receives all the substances necessary for growth from the seed, thus, on the basis of its own nutrients, it is able to grow up to 2 weeks, which makes it possible to grow environmentally friendly products without the use of substrates and nutrient solutions.

In moist seeds, there is an active consumption of oxygen, which stimulates germination, the intensity of aerobic processes increases, oxidases activate, the mitochondria respiratory activity increases to obtain energy during respiration [13, 14]. Therefore, we researched the effect of saturation of the nutrient solution with oxygen on the quantitative and qualitative indicators of microgreen production. 


\section{Experimental}

To research the influence of dissolved oxygen on microgreen productivity, a test bench was developed (Fig. 1). It has 3 independent compartments for conducting a comparative analysis of microgreen growing with the possibility of gas saturation of the root zone:

- control variant - without saturation (oxygen concentration $1.3 \mathrm{mg} / \mathrm{l}$ );

- $\quad$ saturation with air (oxygen concentration 6.1 $\mathrm{mg} / \mathrm{l})$;

- saturation with oxygen (oxygen concentration of $14.7 \mathrm{mg} / \mathrm{l})$.

Each of the three containers has a mesh base on which plant seeds are partially immersed in water. The base has holes for the growth of the root part of plants, falling into the container. There are aeration nozzles at the base of containers 2 and 3. Through these nozzles, ambient air is supplied to the plant roots in a container 2 and oxygen in container 3. Oxygen was obtained in the membrane electrolyzer which made it possible to abandon the use of gas cylinders to saturate the solution with oxygen. The use of the electrolyzer is safe and can also be used in domestic conditions. The electrolyzer of this type has compact dimensions and can be used in serial installation used for growing microgreens or sprouts.

The oxygen concentration in water was measured using an Expert-001-4 instrument with a Clark sensor DKTP-02.4 with a measurement accuracy of $0.1 \mathrm{mg} / \mathrm{l}$.

The experiment was conducted at the test bench, in each compartment of which, in the first series of experiments (3 replicates), 1000 seeds of spring wheat (Triticum aestivum L.) seeds of the "Ivolga" variety were planted, in the second series of experiments - 100 lentil (Lens culinaris Medik.) seeds of 'Aida' variety in order to study the effect of dissolved oxygen on microgreen productivity (development of productive shoots and root system). All compartments of the stand were evenly lit by natural sunlight. Daily, the number of germinated seeds was recorded, after 7 days of cultivation, samples were taken of 10 plants in each diagonal of a rectangular container to take into account the growth parameters and determine the dry weight of the sample, 3 samples were taken in the same way to determine the quantitative content of pigments. To determine the dry matter mass in plants, the sample was ground and dried in an oven at a temperature of $105{ }^{\circ} \mathrm{C}$ for 1 hour. Weighing of the samples was carried out on an analytical balance with accuracy of $0.0001 \mathrm{~g}$. A quantitative analysis of pigments was carried out by extraction from plant tissues using a solvent (100\% acetone), separation of the mixture into individual components and spectrophotometry.

The results were processed using one-way analysis of variance (Tukey's HSD test) using Microsoft Excel 2016.

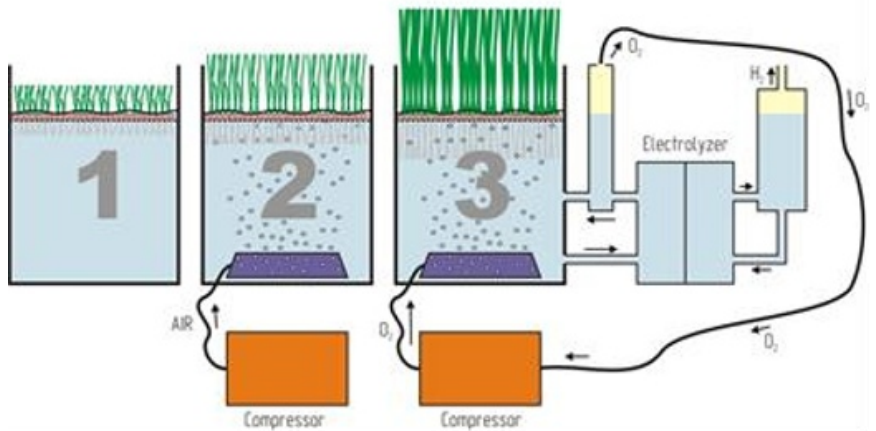

Fig. 1. Scheme of the test banch (1 - without saturation, 2 saturation with air, 3 - saturation with oxygen)

\section{Results and discussion}

Before carrying out the experiment, we carried out preliminary experiments to determine the laboratory germination of seeds (4 replications of 100 seeds). Laboratory germination of wheat was $99 \%$, lentils - 95 $\%$. The main experience showed that oxygen concentration did not affect the germination of seeds of both species, but significantly accelerated the rate of germination. Already on the 2 nd day of vegetation, fullfledged sprouts were obtained in variant with oxygen saturation, which is 1 day faster than in the other variants of the experiment. On day 3 , in the variant with oxygen saturation, the microgreen reached $2-3 \mathrm{~cm}$, it was already prepared for consumption (Fig. 2).

For the purity of the experiment, the evaluation of the results was carried out 7 days after sowing (according to the standard terms for obtaining products).

The increase in oxygen concentration had a significant effect on the root system development of both cultures (Table I). It was established that an increase in oxygen concentration contributed to the rapid growth of the root system, and for lentils, which have a taproot, stimulated the formation of roots of the 2 nd order.

An increase in the root suction surface accelerated the development of the overhead parts of plants: the average height of the wheat plants increased by $29 \%$ with air saturation and $64 \%$ with oxygen saturation, the average height of the lentil plants increased by $64 \%$ and $91 \%$, respectively (Table 2 ).

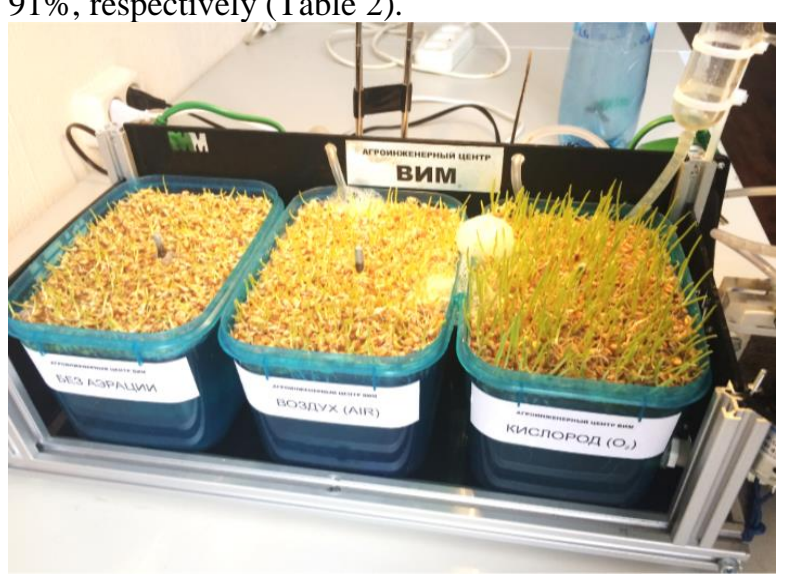

Fig. 2. Sprouts of spring wheat cultivar 'Ivolga' on the 3rd day after sowing (from left to right: without aeration, air saturation, oxygen saturation) 
The average in repetitions wet weight of the wheat plant overhead part increased by $21 \%$ with air saturation and by $56 \%$ when saturated with oxygen, lentils by 57 $\%$ and $77 \%$, respectively, while the losses in the percentage of dry matter are negligible (1-2 \%) Therefore, the developed method of growing does not lead to a loss of microgreen quality.

An increase in the oxygen concentration in water had a significant positive effect on the content of chlorophyll $\mathrm{a}$ in wheat microgreens (Ccl.a $=0.017$ in the variant without aeration, 0.026 when saturated with air and $0.035 \mathrm{mg} / \mathrm{g}$ when saturated with oxygen), and did not significantly affect the concentration of chlorophyll b and carotenoids (Fig. 3). As for lentils, the highest content of all 3 pigments was observed in the variant with aeration by air, which allows us to conclude that both the lack and excess of oxygen in the water negatively affects these indicators.

Thus, experience shows the species-specificity of the effect of oxygen concentration on the content of basic pigments.

\section{Conclusion}

In the course of research, it was found that enrichment of water for seed germination with oxygen stimulates the speedy germination and receipt of sprouts of wheat and lentils 1 day faster than in the variant without saturation.

An increase in oxygen concentration contributes to the rapid growth of the root system of the studied cultures, and for plants with a taproot, it stimulates the formation of 2-order roots. Increasing concentration of oxygen also accelerates the development of the overhead parts of plants, without loss of dry mass.
An increase in the concentration of oxygen in water has a significant effect on the content of basic pigments in microgreens. However, both a deficiency and an excess of oxygen in water can adversely affect these indicators, and the reaction to the concentration is species-specific. Thus, it is necessary to select the species composition of the cultures for the preparation of multicomponent mixtures, to obtain higher quality microgreen for functional nutrition when grown on oxygen-enriched solutions.

An increase in the oxygen concentration in the solution enlarges the mass and nutritional value of microgreen, and the developed oxygen enrichment devise is safe and compact, which makes it possible to recommend it both for industrial plants and for domestic use.

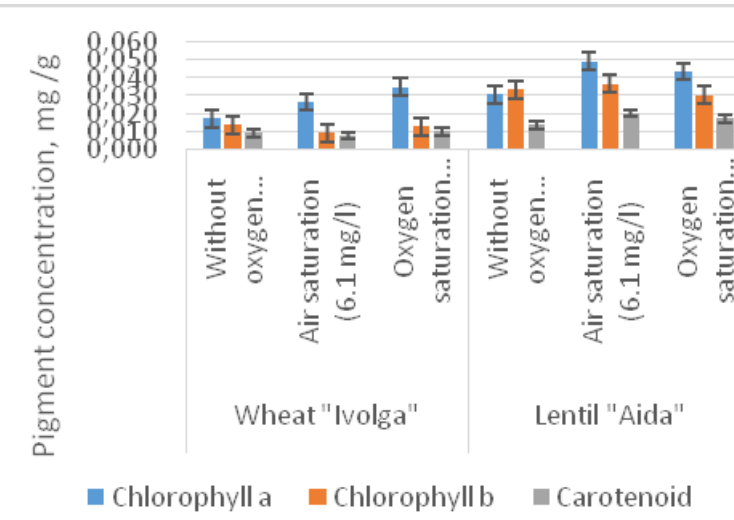

Fig. 3. The content of the main pigments (chlorophyll a, chlorophyll $\mathrm{b}$ and carotenoids) in the microgreen of wheat of the Oriole variety and lentils of the Aida

TABLE 1. Root growth indicators of 'Aida' lentil and 'Ivolga' wheat microgreens cultivated with immersion of the root system in water with various oxygen concentrations on 7 th day after seeding

\begin{tabular}{|c|c|c|c|}
\hline \multirow{2}{*}{ Crop, variety } & Test options (oxygen concentration, mg/l) & $\begin{array}{c}\text { Average total root } \\
\text { length, cm }\end{array}$ & $\begin{array}{c}\text { Average total } \\
\text { number of roots }\end{array}$ \\
\hline \multirow{3}{*}{ Lentils "Aida" } & Without oxygen saturation $(1.3 \mathrm{mg} / \mathrm{l})$ & 1.30 & 1.0 \\
\cline { 2 - 4 } & Air saturation $(6.1 \mathrm{mg} / \mathrm{l})$ & 4.87 & 3.2 \\
\cline { 2 - 4 } & Oxygen saturation $(14.7 \mathrm{mg} / \mathrm{l})$ & 5.69 & 5.2 \\
\hline \multirow{3}{*}{ Wheat "Ivolga" } & Least significant difference $(\mathrm{P}<0.05)$ & 4.18 & 1.4 \\
\cline { 2 - 4 } & Without oxygen saturation $(1.3 \mathrm{mg} / \mathrm{l})$ & 6.53 & 5.6 \\
\cline { 2 - 4 } & Air saturation $(6.1 \mathrm{mg} / \mathrm{l})$ & 18.76 & 5.0 \\
\hline \multicolumn{2}{|c|}{ Oxygen saturation $(14.7 \mathrm{mg} / \mathrm{l})$} & 2.37 & 0.5 \\
\hline
\end{tabular}

TABLE 2. Growth overhead indicators of 'Aida' lentil and 'Ivolga' wheat microgreens cultivated with immersion of the root system in water with various oxygen concentrations on 7 th day after seeding.

\begin{tabular}{|c|c|c|c|c|}
\hline Crop, variety & Test options (oxygen concentration, mg/l) & $\begin{array}{l}\text { Average } \\
\text { shoot } \\
\text { length, cm }\end{array}$ & $\begin{array}{c}\text { Average green } \\
\text { plant mass, } g\end{array}$ & $\begin{array}{c}\text { Dry weight, } \\
\%\end{array}$ \\
\hline \multirow{3}{*}{ Lentils Aida } & Without oxygen saturation $(1.3 \mathrm{mg} / \mathrm{l})$ & 4.35 & 0.041 & 13.1 \\
\hline & Air saturation $(6.1 \mathrm{mg} / \mathrm{l})$ & 7.15 & 0.064 & 12.0 \\
\hline & Oxygen saturation $(14.7 \mathrm{mg} / \mathrm{l})$ & 8.37 & 0.072 & 13.4 \\
\hline \multicolumn{2}{|c|}{ Least significant difference $(\mathrm{P}<0.05)$} & 1.41 & 0.012 & - \\
\hline \multirow{3}{*}{$\begin{array}{l}\text { Wheat } \\
\text { Ivolga }\end{array}$} & Without oxygen saturation $(1.3 \mathrm{mg} / \mathrm{l})$ & 6.91 & 0.048 & 13.5 \\
\hline & Air saturation $(6.1 \mathrm{mg} / \mathrm{l})$ & 8.94 & 0.058 & 11.8 \\
\hline & Oxygen saturation $(14.7 \mathrm{mg} / \mathrm{l})$ & 11.26 & 0.075 & 11.7 \\
\hline \multicolumn{2}{|c|}{ Least significant difference $(\mathrm{P}<0.05)$} & 1.18 & 0.009 & - \\
\hline
\end{tabular}




\section{References}

1. N. Kamitdinov, Beds up. Who and why build vertical farms in Russian cities, URL: https://incrussia.ru/understand/vertical-farming/

2. T.I. Makeeva, Sprouted grain. Live product at home, Competitiveness of territories: materials of XXII All-Russian. econ. forum of young scientists and students, 1, 197-190 (2019).

3. Z. Xiao, E.E. Codling, Y. Luo, X. Nou, G. E. Lester, Q. Wang, J. Food Compos. Anal. 49, 87 (2016)

4. L. P. Yadav, T. K. Koley, A. Tripathi, S. Singh, Agric. Res. 8(2), 165 (2019)

5. N. L. Waterland, Y. Moon, J. C. Tou, M. J. Kim, E. M. Pena-Yewtukhiw, S. Park, Hortscience 52(4), 566 (2017)

6. C. F. Weber, Front. Nutr. 4, 7 (2017)

7. Z. Xiao, "Nutrition, sensory, quality and safety valuation of a new specialty produce: microgreens",
Doctoral dissertation, Faculty of the Graduate School of the University of Maryland, 2013

8. E.R. Turner, Y. Luo, R. L. Buchanan, J. Food Sci. 85(4), 870 (2020)

9. N.Y. Stepanova, News of St. Petersburg State Agrarian University, 41, 56-64 (2015).

10. H.Q. Huang, X.J. Jiang, Z.L. Xiao, L. Yu, Q. Pham, J.H. Sun, P. Chen, W. Yokoyama, L.L.L. Yu, Y.S. Luo, T. T. Y. Wang, J. Agric. Food. Chem. 64(48), 9161 (2016)

11. R.T. Timakova and T.I. Makeeva, "Features of the technology of growing microgreen wheat and milk thistle", E-FORUM, 1, 79- 89 (2020).

12. A.S. Dmitrieva, Chronoeconomics 6(19), 35-38 (2019)

13. V.V. Rogozhin, T.T. Kurilyuk, T.V. Rogozhina, Agricultural Biology, 47(1), 60 (2012)

14. G.A. Plutakhin, K.P. Fedorenko, and Y.D. Molchanov, Political network electronic scientific journal of the Kuban State Agrarian University, 100, 276-290 (2014). 